\title{
Experimental and numerical analysis of the effect of gear center distance variation and misalignment error on the dynamic behavior of narrow-faced spur gear drives
}

\author{
Mohamed Ben Amar, Mohamed Maatar and Aref Maalej \\ Laboratory of Electro-Mechanical System, LASEM, École Nationale d'Ingénieurs de Sfax, BP W 3038, Sfax, Tunisie
}

Received 29 May 2002, Accepted 8 July 2005

\begin{abstract}
In this paper, we present an experimental and numerical analysis of the influence of gear center distance variation and misalignment amplitude on dynamic response of single stage spur gear transmission systems. The experimental part is conducted on a specific test bench conceived and constructed at LASEM and composed essentially of a motor, a test gearbox and a receptor. It allows the measurement of the acceleration on the motor and receptor bearing shafts for different values of gear center distances and misalignment amplitudes. The numerical study is based on a 3D non-linear model with 36 degrees of freedom including torsional, flexural and axial displacements of the gear-shaft-bearing system. The equations of motion and the contact problem are solved simultaneously using an original procedure by coupling a normal contact algorithm and a numerical Hilbert-Hughes-Taylor schema. Agreement between measurements and calculations is satisfactory and illustrates the influence of these mounting errors on the dynamic behavior of Narrow-Faced Spur Gear.
\end{abstract}

Key words: Spur gear transmission / misalignement errors / gear centers distance variation / non-linear dynamic model / modal analysis / experimental and numerical dynamic responses

\section{Introduction}

The dynamic behavior of gear transmission is generally conditioned by the perturbations produced by the different parts of the system (gear, motor, bearing, ... ). The two kinds of geometrical errors, generally found in gear transmission systems, are manufacturing defaults (pitch errors, profile and distorsion errors, ...) and mounting errors (eccentricities, misalignment, gear center distances, ... ). It is well known that gear transmission design imposes a variation of the gear center distances because of permitted tolerance intervals. In fact, the functional gear center distance is different from the theoretical one. The variation of gear center distances modifies the length of the contact pattern on the base plane and generally causes a premature or backward contact. Consequently, the value of transverse contact ratio changes considerably. Misalignment has an important influence on the dynamic load distribution of mating teeth and on the gear vibration. For important amplitude of misalignment, we can show a partial contact through the face width with a strong concentration on one edge of the flanks. As a result of this partial contact, a decrease of mesh stiffness is occurring and consequently the mesh resonance frequencies become lower.
Experimental and numerical studies are proposed to analyze the influence of these mounting errors on the dynamic behavior of gear transmission systems. First, measurements of the dynamic response for different error amplitude and input rotational speed will be presented. Next, a series of numerical results, obtained at the same conditions, using a numerical tool developed by Maatar and Velex P. [1,2] will be compared to these measurements.

\section{Non-linear dynamic model}

In this specific model, pinion and wheel are simulated as rigid cylinders connected by an elastic and dissipative link. Potential contact lines on the base plane are discretized in independent elementary cells of normal stiffness $\left(k_{i}\right)$. According to this discretization, mesh stiffness is time-dependent because of contact length evolutions and non-linear as contact length depends on actual tooth loading and geometrical deviations on mating surfaces.

The contact deflection $\Delta_{i}\left(M_{i}\right)$ at the potential point of contact $M_{i}$ depends on the normal approach induced by 
the degrees of freedom $\delta\left(M_{i}\right)$ and the relative composite geometrical deviation $\delta e\left(M_{i}\right)$

$$
\begin{aligned}
\Delta\left(M_{i}\right) & =\delta\left(M_{i}\right)+\delta e\left(M_{i}\right) \\
\delta\left(M_{i}\right) & =\left\{V\left(M_{i}\right)\right\}^{T}\{q\} \\
\delta e\left(M_{i}\right) & =e\left(M^{*}\right)-e\left(M_{i}\right)
\end{aligned}
$$

With

$\{q\}$ : coordinate vector associated with the gear,

$\left\{V\left(M_{i}\right)\right\}$ : structure vector depending on gear geometry,

( $k i$ ): elementary mesh stiffness of the cell centered in $M_{i}$, $e\left(M^{*}\right)$ : composite deviation at $M^{*}$ - one point of contact in rigid body condition,

$e\left(M_{i}\right)$ : composite deviation at $M_{i}$ - potential point of contact in the deformed state.

The instantaneous contact condition at the potential point $M_{i}$ is:

$$
\Delta\left(M_{i}\right)>0
$$

The strain energy associated with the mesh can be given by:

$$
\begin{aligned}
U_{G}= & \frac{1}{2} \sum_{i} k_{i} H\left[\Delta\left(M_{i}\right)\right] \Delta^{2}\left(M_{i}\right) \\
= & \frac{1}{2}\{q\}^{T}\left[\sum_{i} k_{i} H\left[\Delta\left(M_{i}\right)\right]\left\{V\left(M_{i}\right)\right\}\left\{V\left(M_{i}\right)\right\}^{T}\right] \\
& \times\{q\}-\{q\}^{T} \sum_{i} k_{i} H\left[\Delta\left(M_{i}\right)\right] \\
& \delta e\left(M_{i}\right)\left\{V\left(M_{i}\right)\right\}+\frac{1}{2} \sum_{i} k_{i} H\left[\Delta\left(M_{i}\right)\right] \delta^{e^{2}}\left(M_{i}\right)
\end{aligned}
$$

where $H\left[\Delta\left(M_{i}\right)\right]$ is the unit Heaviside function defined by:

$$
\left\{\begin{array}{l}
H(\Delta)=1 \text { if } \Delta>0 \\
H(\Delta)=0 \text { if } \Delta \leq 0
\end{array}\right.
$$

Using Lagrange equations leads to:

$$
\begin{gathered}
\frac{\mathrm{d}}{\mathrm{d} t}\left(\frac{\partial T_{G}^{R o}}{\partial \dot{q}_{k}}\right)-\left(\frac{\partial T_{G}^{R o}}{\partial q_{k}}\right)=[M]\{\ddot{q}\}-\left\{F_{1 G}\right\} \\
k=1,2, \ldots, 12 \\
\frac{\partial U_{G}}{\partial q_{k}}=\left[K_{G}(t,\{q\})\right]\{q\}-\left\{F_{2 G}(\{q\})\right\}
\end{gathered}
$$

The global equations of motion obtained after assembly of the gear, shafts and bearing matrices is:

$$
\begin{aligned}
& {[M]\{\ddot{X}\}+[C]\{\dot{X}\}+[}K(t, X)]\{X\}= \\
&\left\{F_{\text {ext }}\right\}+\left\{F_{1 G}\right\}+\left\{F_{2 G}\right\}
\end{aligned}
$$

where:

$$
\{X\} \text { : coordinate vector for the complete system. }
$$

The damping matrix is introduced in the equations of motion through modal damping factor. The mode shapes

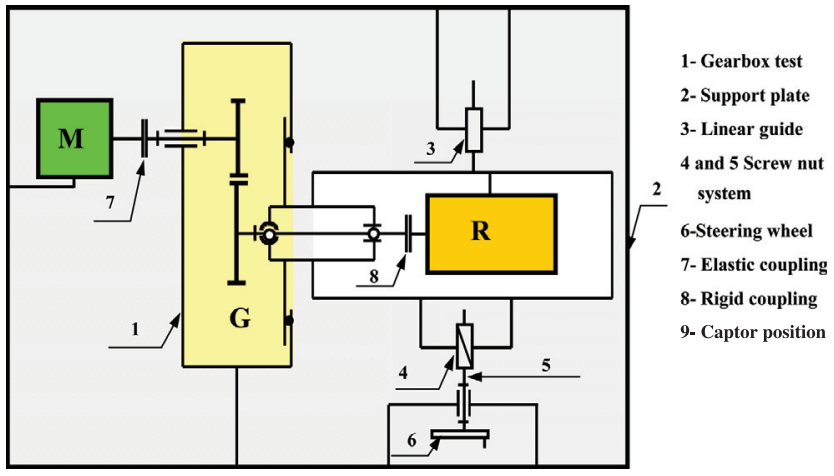

Fig. 1. Test bench schema.

Table 1. Geometric characteristics of gearbox.

\begin{tabular}{ll}
\hline Numbers of teeth in pinion and wheel & $Z_{1}=Z_{2}=50$ \\
Module & $m=1 \mathrm{~mm}$ \\
Addendum coefficient & $h a=1$ \\
Dedendum coefficient & $h f=1.4$ \\
Pressure angle & $\alpha=20$ degrees \\
Face width & $b=20 \mathrm{~mm}$ \\
Quality of gears & class $=7-8$ \\
Transverse contact ratio & $\varepsilon \alpha=1.75$ \\
Young modulus & $E=2.1 \times 10^{11} \mathrm{~N}_{\mathrm{m}} \mathrm{m}^{-2}$ \\
Poisson's ratio & $\nu=0.3$ \\
Density & $\rho=7850 \mathrm{~kg} . \mathrm{m}^{-3}$ \\
\hline
\end{tabular}

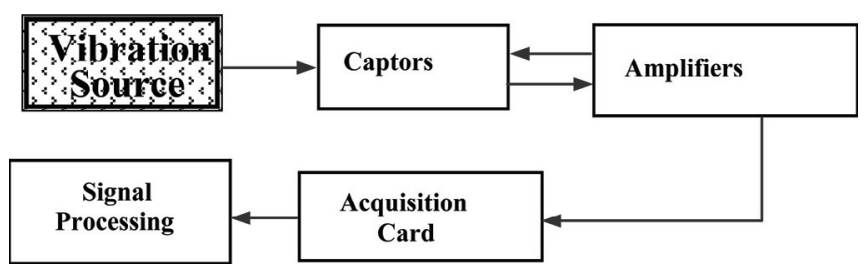

Fig. 2. Acquisition flow-charts and signal treatment.

are calculated using averaged linear mesh stiffness. The differential equation system (8) is solved by combining a numerical Hilbert-Hughes-Taylor schema and an unilateral normal contact algorithm [3] controlling if contact deflection in every potential contact point $M_{i}$ is positive or negative and consequently finds the instantaneous contact zone.

\section{Experimental set-up}

A specific gear test bench developed in LASEM is used (Fig. 1).

The characteristics of pinion and wheel are listed in Table 1.

The analysis of dynamic behavior of gear transmission is affected by a data acquisition system presented in Figure 2. The signal treatment is done after acquisition of acceleration signals by (piezo-electric) captors planted in suitable and valuable places on gear test bench [4]. Figure 1 shows the location of engine bearing captor which is used to acquire all the experimental results. An engine 

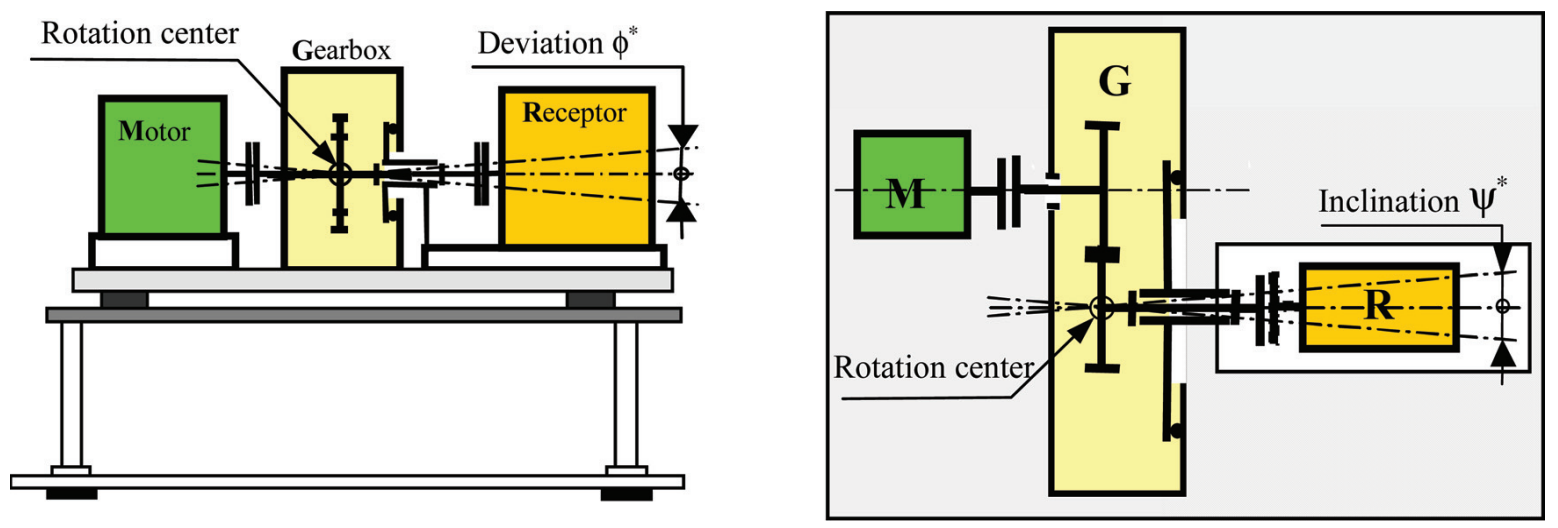

Fig. 3. Experimental procedure of variation of misalignment errors.

Table 2. Numerical main natural frequencies of gear test bench.

\begin{tabular}{ccccc}
\hline $\begin{array}{c}\text { Mode } \\
\mathrm{n}^{\circ}\end{array}$ & $\begin{array}{c}\text { Natural } \\
\text { frequencies } \\
(\mathrm{Hz})\end{array}$ & $\begin{array}{c}\text { Input rotational } \\
\text { speed } \\
(\mathrm{rpm})\end{array}$ & Concerned elements & Strain energy proportion \\
\hline 1 & 11828 & 14160 & Gear & 0.86 \\
2 & 4765 & 5713 & Driven shaft & 0.98 \\
3 & 4534 & 5350 & Driving shaft & 0.86 \\
4 & 2532 & 3038 & Driving shaft & 0.94 \\
5 & 2370 & 2837 & Driving and & 0.73 and \\
& & & Driven shaft & 0.2 \\
6 & 1784 & 2140 & Driven shaft & 0.93 \\
7 & 1729.2 & 2075. & Driven shaft & 0.92 \\
8 & 1246.3 & 1496. & Driven shaft + Motor & $0.51+0.32$ \\
& & & bearing & 0.998 \\
9 & 931.7 & 1118. & Motor bearing & 0.86 \\
10 & 921. & 1105. & Motor bearing & $0.6+0.32$ \\
11 & 897.3 & 1077. & Receptor and Motor & bearing \\
& & & Receptor bearing & 0.90 \\
12 & 883.9 & 1061. & Receptor bearing & 0.98 \\
13 & 708.3 & 850. & Driven shaft & 0.97 \\
14 & 169. & 203. & Driven shaft & 0.97 \\
\hline
\end{tabular}

torque of $36.4 \mathrm{~N} \mathrm{~m}$ is used to study the static and dynamic behavior of spur gear drives.

The gear center distance variation is, experimentally, done using a screw-nut system (4) and (5) (Fig. 1). This system permits to give a continuous variation of the gear center distances between 0 and $96 \mathrm{~mm}$ with precision of $0.02 \mathrm{~mm}$.

The misalignment errors are, experimentally, introduced by the inclination or the deviation of the driven shaft. The experimental procedure, which permits the inclination and deviation variation on the test bench, is presented in Figure 3.

\section{Modal analysis}

The criterion used to select the significant modes is based on the percentage of strain energy stored in every element of geared system [6]. For the $i$ th mode, the percentage of strain energy stored in the $j$ th element of the system is given by:

$$
\rho_{i j}=\frac{\left\{\phi_{i}\right\}^{\mathrm{T}}\left[K_{j}\right]\left\{\phi_{i}\right\}}{\left\{\phi_{i}\right\}^{\mathrm{T}}\left[K_{\mathrm{T}}\right]\left\{\phi_{i}\right\}}
$$

$\{\phi i\} i$ th mode vector

$\left[K_{J}\right]$ mean stiffness matrix of the $j$ th element of geared system

$\left[K_{\mathrm{T}}\right]$ mean stiffness matrix of the global geared system

The main mode shapes of the gear test bench calculated numerically are represented in Table 2 . It was found that critical frequencies, which may be considered occurring as a result of the internal excitation caused by the time stiffness variation, correspond to the condition $[3,5,8]$ :

$$
i \varpi_{\mathrm{m}}=\varpi_{\mathrm{n}}
$$

Because of geometrical errors, other critical frequencies can occur when fundamental error frequency and its higher harmonics coincide with a natural frequency.

$$
j \varpi_{\mathrm{e}}=\varpi_{\mathrm{m}}
$$




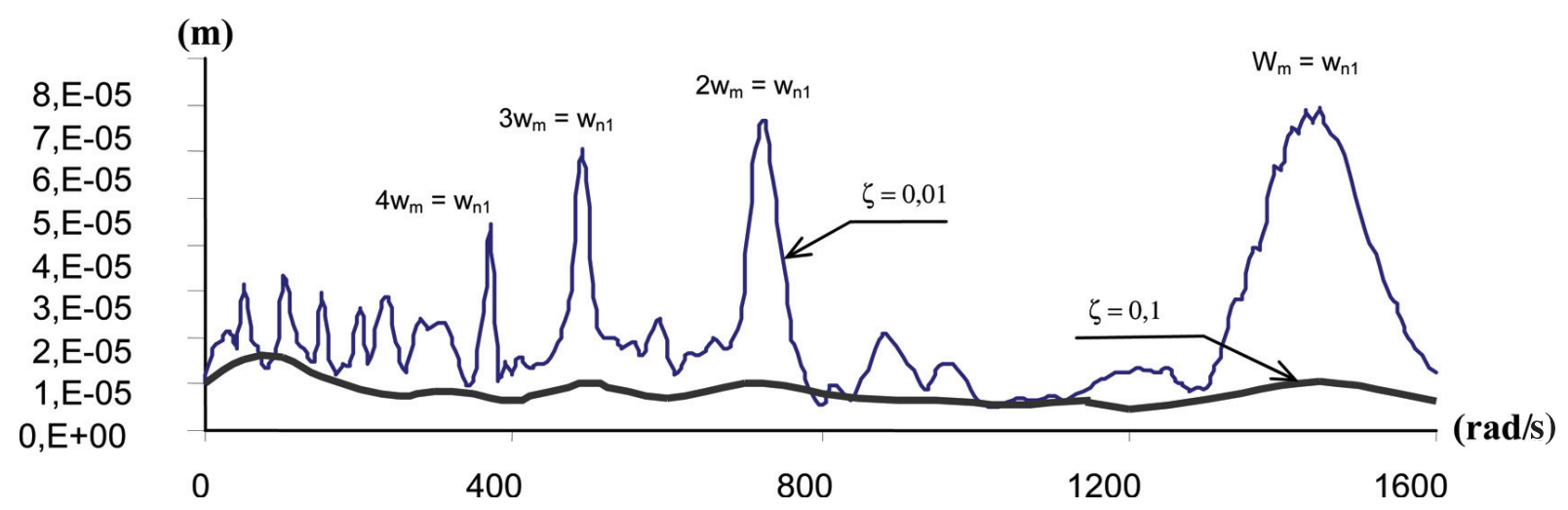

Fig. 4. Peak to peak gear transmission error $(\mathrm{m})$ under load as a function of pinion rotational speed $\left(\mathrm{rad} . \mathrm{s}^{-1}\right)$.

As a result of these internal excitations we can write:

$$
j \varpi_{\mathrm{e}} \pm i \varpi_{\mathrm{m}}=\varpi_{\mathrm{n}}
$$

$\varpi_{\mathrm{n}}$ : natural frequencies

$\varpi_{\mathrm{m}}$ : meshing frequency

$\varpi_{\mathrm{e}}$ : fundamental geometrical error frequency

The relationship between pinion rotational frequency and meshing frequency is:

$$
\varpi_{\mathrm{m}}=Z_{1} \Omega_{1}
$$

$\Omega_{1}$ : pinion rotational frequency

$Z_{1}$ : pinion tooth number

Figure 4 shows the variation of the numerical peakto-peak gear transmission error for different values of input rotational speed. In order to clearly show the critical speeds, a low modal damping factor $\zeta=0.01$ is considered in the numerical simulation. It can be seen from Figure 4 that potential resonance speeds are generated by meshing frequency $\omega_{\mathrm{m}}$ and its three higher harmonics $j \cdot \omega_{\mathrm{m}}(j=2,3$ and 4$)$ which coincides with the highest natural frequency $\omega_{\mathrm{n} 1}$ corresponding to gear mode. The amplitude builds up so rapidly that complete separation of teeth occurs and consequently impact takes place and possibly generates destruction of teeth. We remark, also the presence of secondary critical speeds influencing gear vibration. These critical speeds take place when meshing frequency coincides with the lowest natural frequencies corresponding to the other mode shape (shafts and bearing modes).

\section{Results and discussion}

\subsection{Gear centers distance variation}

For the tested gear (Tab. 1), theoretical gear center distance is equal to $50 \mathrm{~mm}$; the input torque is $36.4 \mathrm{Nm}$ and the input rotational speed is $1000 \mathrm{rpm}$. The radial acceleration captor is placed at the level of motor bearing. Figure 5 shows the experimental and numerical spectrum of radial acceleration $\left(\mathrm{m} . \mathrm{s}^{-2}\right)$ versus frequency $(\mathrm{Hz})$ for the theoretical gear center distances. The numerical spectrum shows two peaks at $833 \mathrm{~Hz}$ and $1666 \mathrm{~Hz}$ corresponding to the mesh frequency and its second harmonic. The experimental spectrum shows, in addition to these two frequencies, an important number of peaks illustrating the resonance of the other elements of the gear system like bearings and shafts.

Figure 6 presents the spectra of radial acceleration within motor bearing with a gear center variation of $+0.5 \mathrm{~mm}$. Good agreement is observed between numerical and experimental spectrums. The two curves show clearly two peaks at $833 \mathrm{~Hz}$ and $1666 \mathrm{~Hz}$ corresponding to the mesh frequency and its second harmonic. As a result of the gear center variation by $+0.5 \mathrm{~mm}$, an amplification of the amplitude of radial acceleration is observed. Figure 7 gives the spectra of radial acceleration within the motor bearing with a gear center variation of $+0.5 \mathrm{~mm}$ for a higher input rotational speed of $1400 \mathrm{rpm}$. We observe in the experimental and numerical spectrums a peak at $1166 \mathrm{~Hz}$, which is equal to the new mesh frequency value. Figure 8 shows the spectra of radial acceleration in motor bearing for an input rotational speed of $1000 \mathrm{rpm}$ and a gear center variation of $+0.2 \mathrm{~mm}$. According to Figures 5, 6 and 8, we can underline that a decrease of gear center distances leads to the decrease of acceleration amplitude.

We note that a variation of the gear center distance by $+0.5 \mathrm{~mm}$ yields to a decrease of the transverse contact ratio $\varepsilon \alpha$ from 1.754 to 1.276 and it reaches 1.559 for a variation of $+0.2 \mathrm{~mm}$.

\subsection{Misalignment errors}

The purpose of this section is to illustrate the influence of shaft misalignment (inclination and deviation) on the dynamic behavior of spur gear system by analyzing the experimental and numerical specta of radial acceleration within motor bearing for different amplitudes of inclination and deviation.

Figure 9 shows the spectra of radial acceleration within the motor bearing with an inclination of $0.4^{\circ}$. Compared to less error spectra (Fig. 5), we remark experimentally and numerically a decrease of acceleration amplitude, we can explain this phenomenon by a positive inclination of $0.4^{\circ}$ which corrects the deflection of 


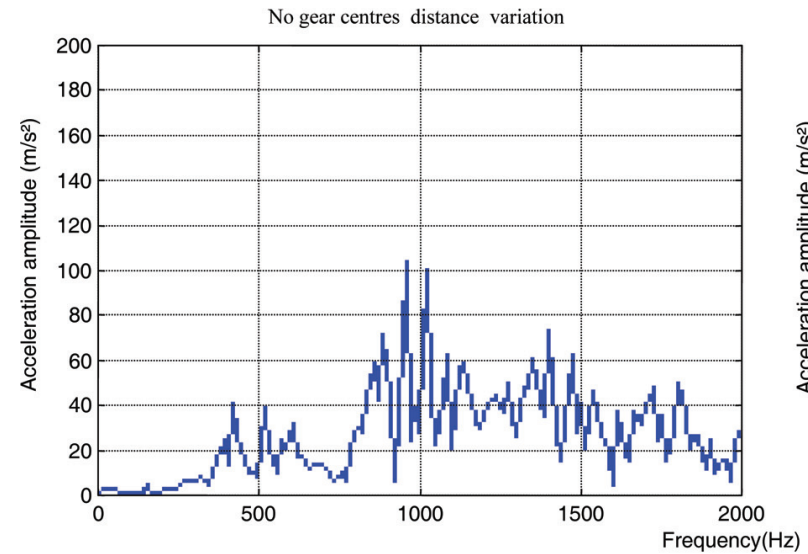

(a)

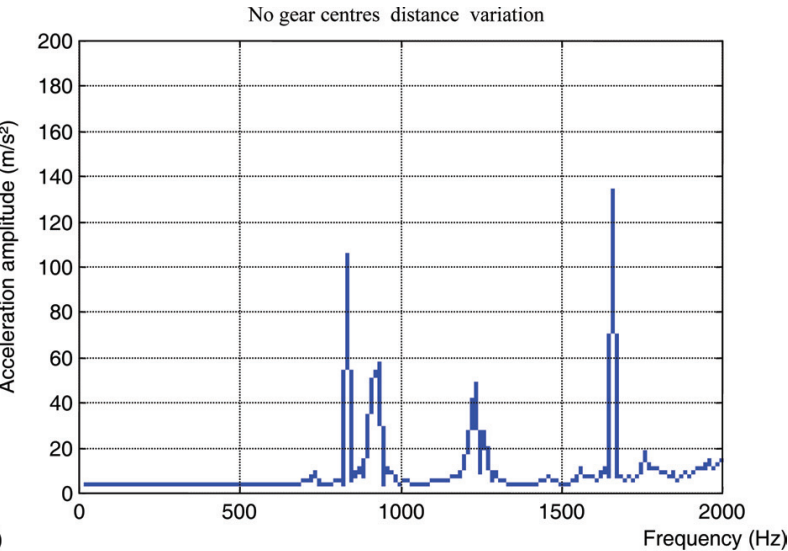

(b)

Fig. 5. Radial acceleration spectra versus frequency (theoretical gear center distance, $\Omega 1=1000$ rpm). a) Experimental spectrum, b) numerical spectrum.

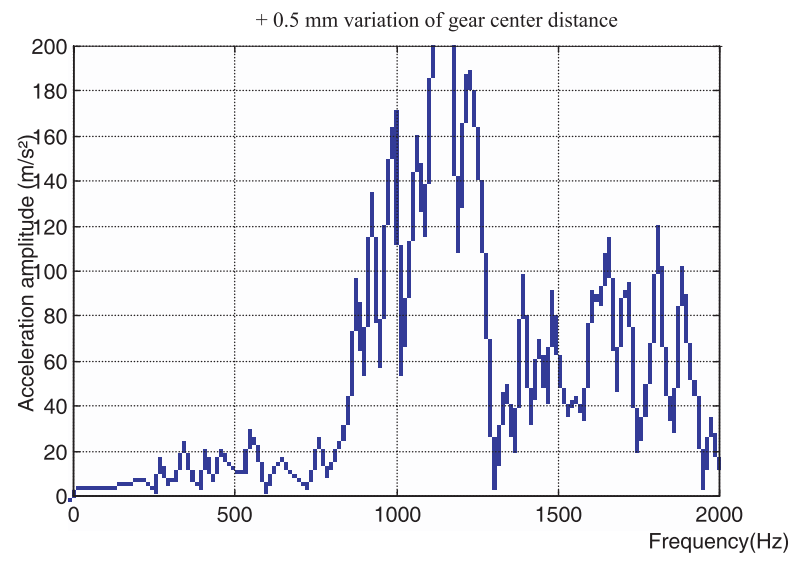

(a)

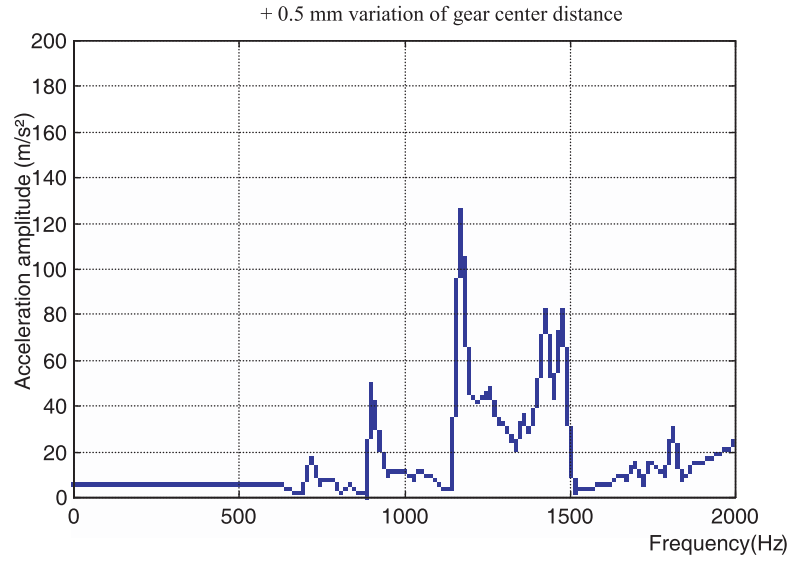

(b)

Fig. 6. Radial acceleration spectra versus frequency (+0.5 mm variation of gear center distance, $\Omega 1=1000 \mathrm{rpm})$. a) Experimental spectrum, b) numerical spectrum.

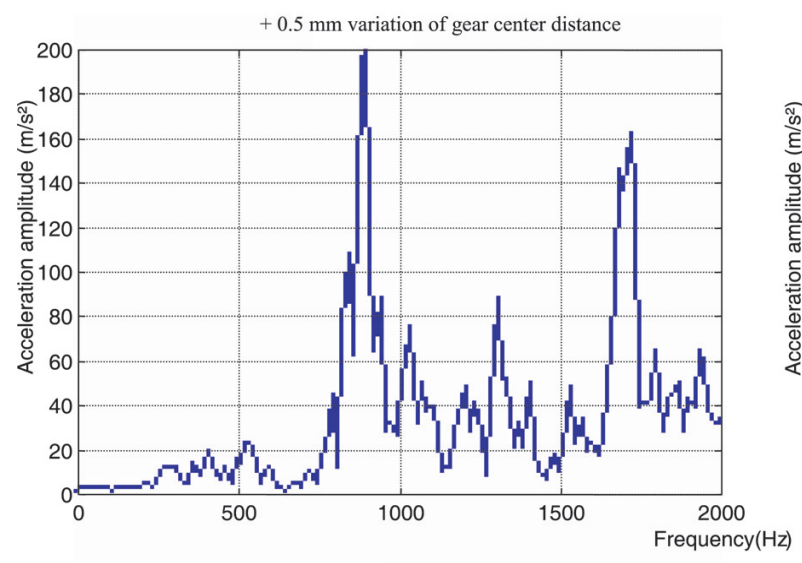

(a)

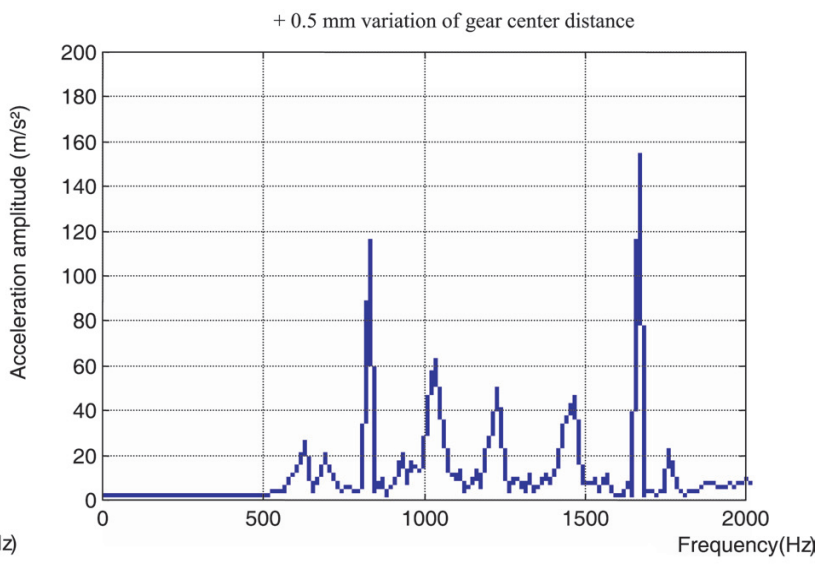

(b)

Fig. 7. Radial acceleration spectra versus frequency (+0.5 mm variation of gear center distance, $\Omega 1=1400 \mathrm{rpm})$. a) Experimental spectrum, b) numerical spectrum. 


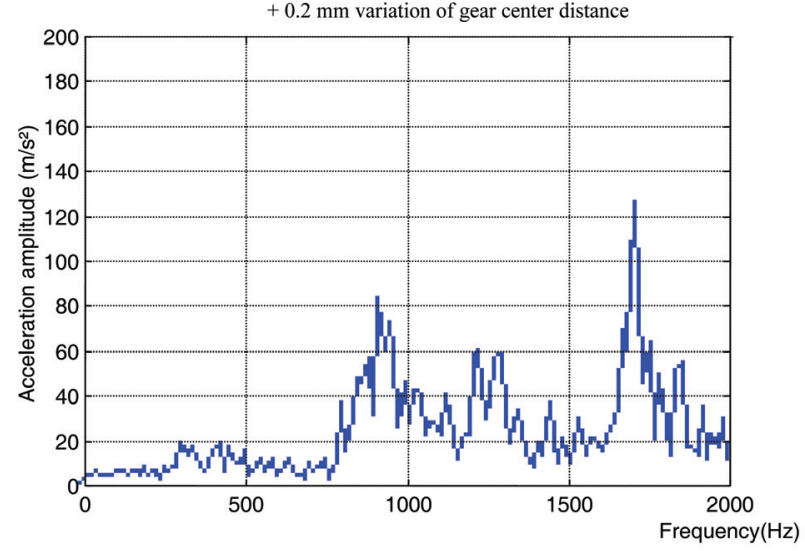

(a)

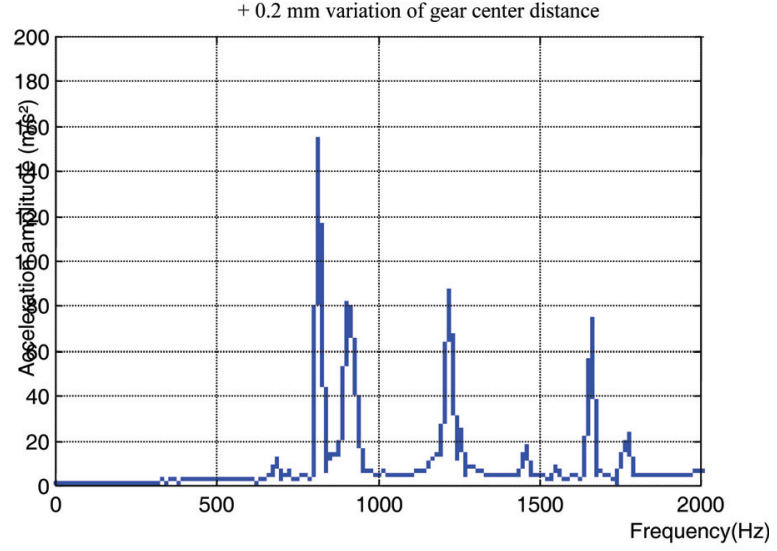

(b)

Fig. 8. Radial acceleration spectra versus frequency (+0.2 mm variation of gear center distance, $\Omega 1=1400 \mathrm{rpm})$. a) Experimental spectrum, b) numerical spectrum.

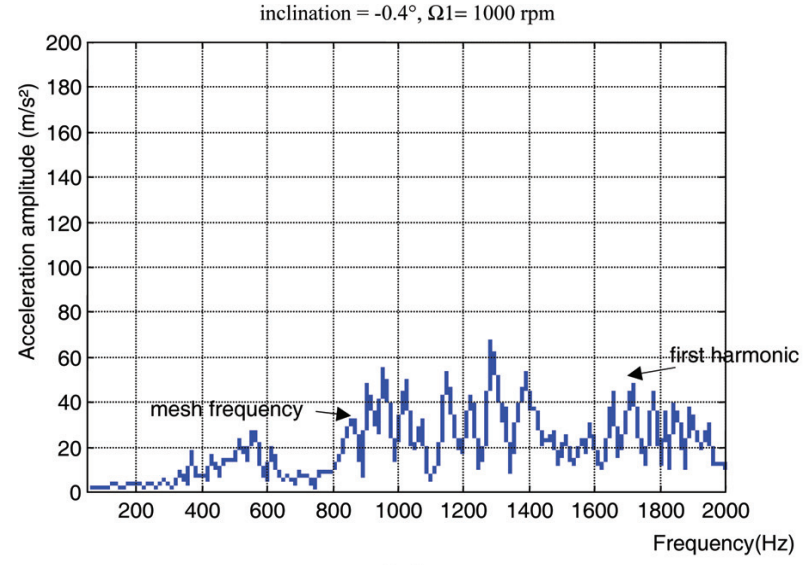

(a)

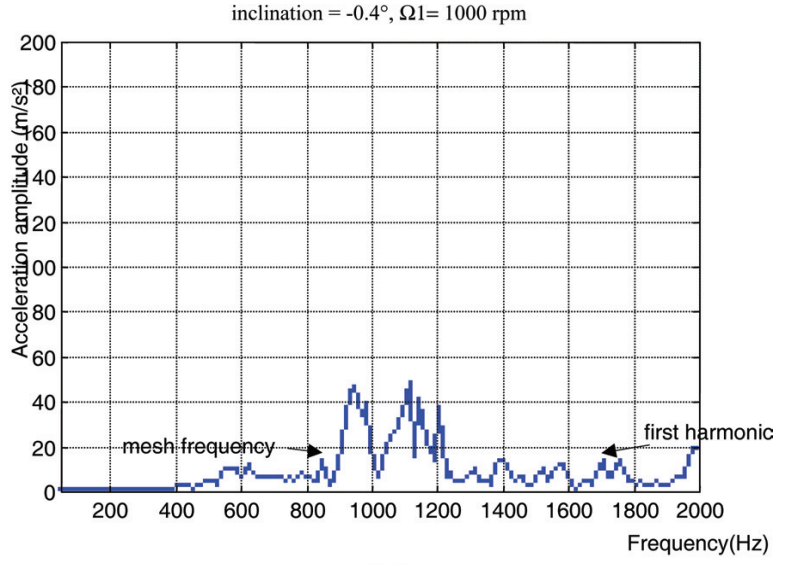

(b)

Fig. 9. Radial acceleration spectra versus frequency (inclination of $0.4^{\circ} \Omega 1=1000 \mathrm{rpm}$ ). a) Experimental spectrum, b) numerical spectrum.

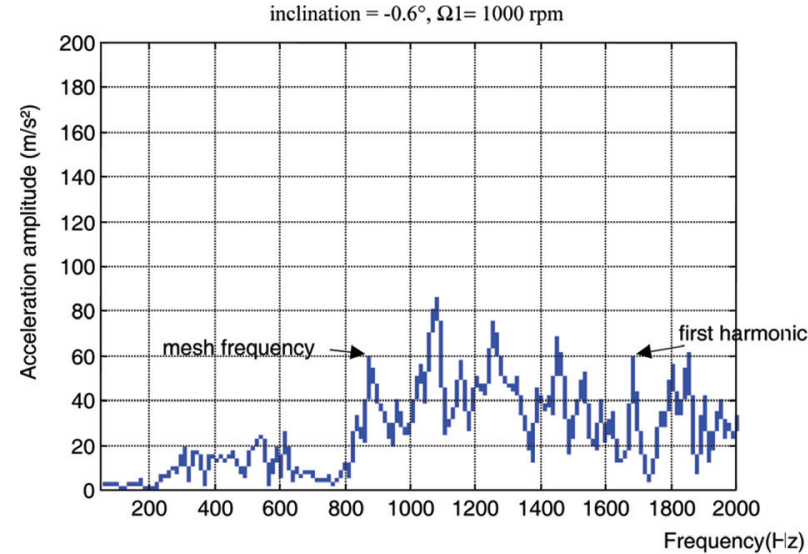

(a)

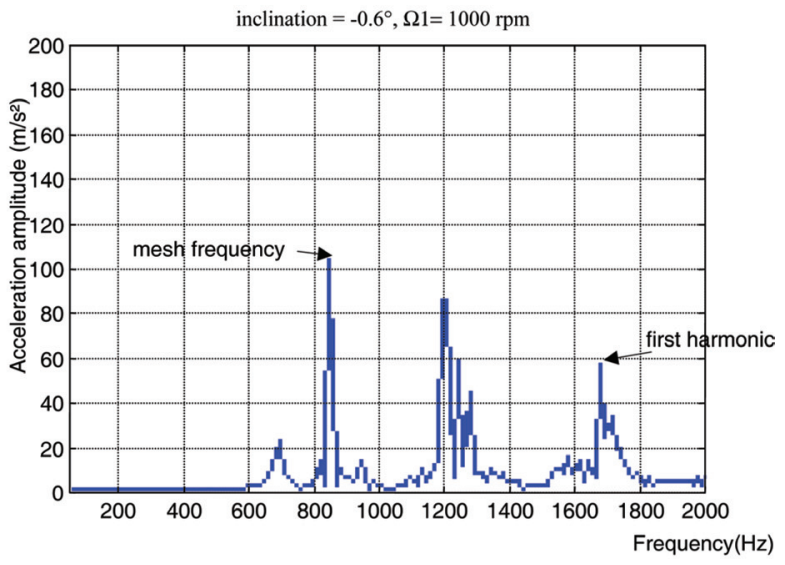

(b)

Fig. 10. Radial acceleration spectra versus frequency (inclination of $0.6^{\circ} \Omega 1=1000 \mathrm{rpm}$ ). a) Experimental spectrum, b) numerical spectrum. 


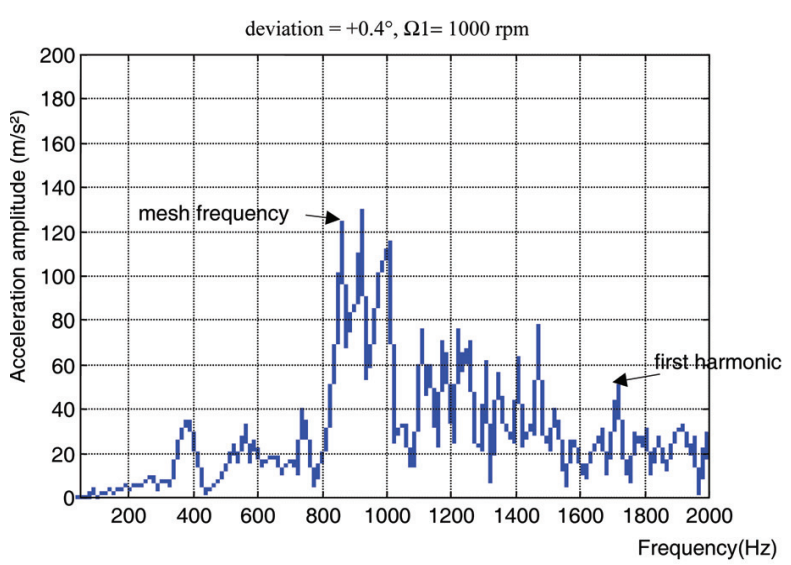

(a)

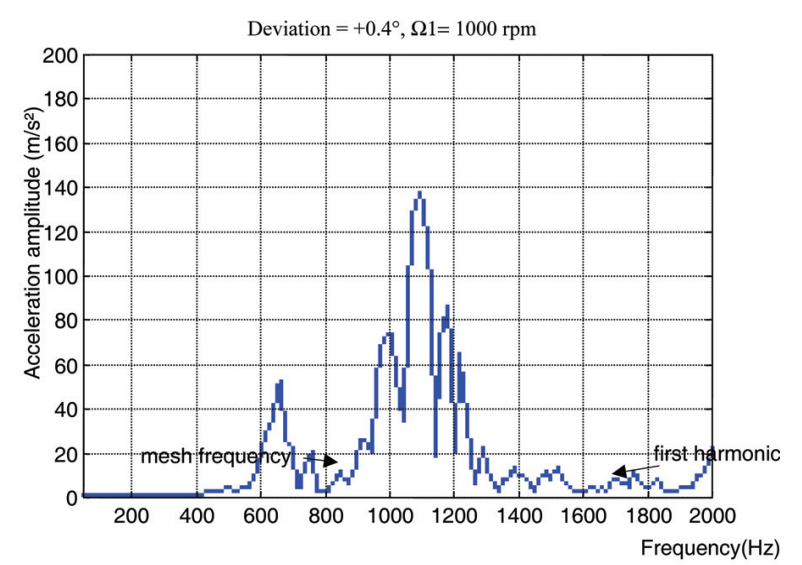

(b)

Fig. 11. Radial acceleration spectra versus frequency (deviation of $0.4^{\circ} \Omega 1=1000 \mathrm{rpm}$ ). a) Experimental spectrum, b) numerical spectrum

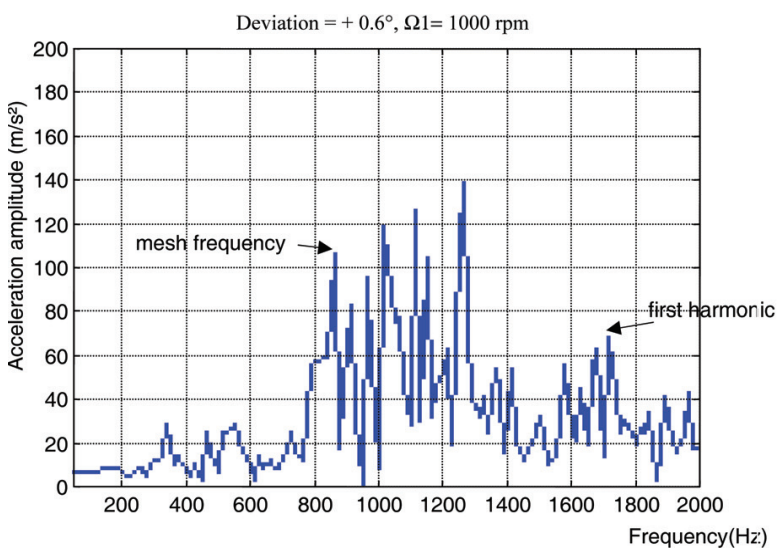

(a)

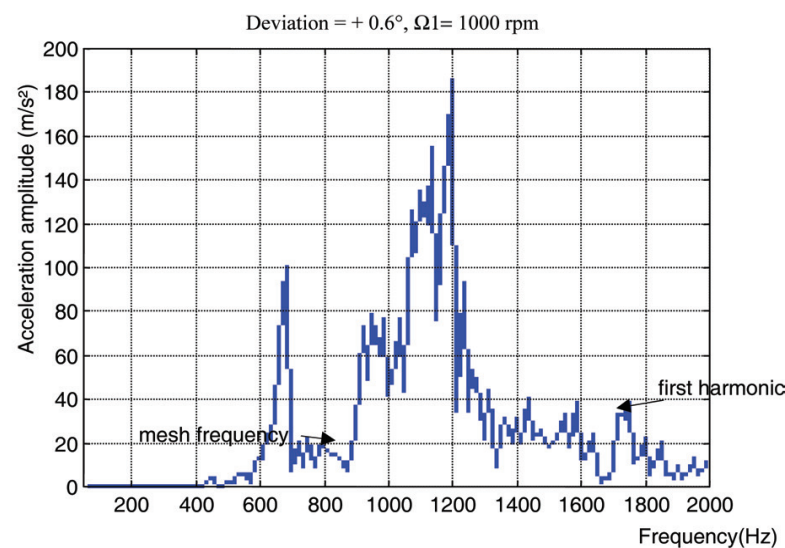

(b)

Fig. 12. Radial acceleration spectra versus frequency (deviation of $0.6^{\circ} \Omega 1=1000 \mathrm{rpm}$ ). a) Experimental spectrum, b) numerical spectrum.

the input shaft having approximately the same angle amplitude but with an opposite sign. When the inclination passes to $0.6^{\circ}$, then the acceleration amplitude increases (Fig. 10). We notice that in the experimental and numerical spectra (Figs. 9 and 10), the existence of an important number of peaks probably induced by other system elements other than the gear which are not considered in he numerical model such as coupling.

Figures 11 and 12 show the radial acceleration spectrum for deviation angles of 0.4 and 0.6 degrees. The comparison between all these spectra leads to the well-known conclusion that deviation is worse than inclination because, for the same value of these defaults, the normal error in base plane caused by a deviation is more important.

\section{Conclusions}

This paper presents an original work on the study of the relationship between vibratory responses of gear systems and some types of mounting errors. The main purpose of this study is to use spectral analysis of responses to predict the geometrical errors (gear center distance and misalignment). The diagnostics of these spectra allow identification of these errors and consequently provide the necessary correction.

Experimental results were first introduced to analyse the dynamic behavior of spur gear system. A nonlinear dynamic model, described in details in [2] and [7], was used for numerical simulations. The measurements were conducted on a specific gear test bench developed in LASEM. A series of numerical and experimental spectra of the radial acceleration within a motor bearing demonstrated that increasing the amplitude of these mounting errors leads to amplifying acceleration amplitudes.

The comparison between the experimental and numerical results was satisfactory. The mesh frequency and its second harmonic were present in the different spectra. In addition to these frequencies, the experimental spectra showed an important number of peaks that were thought to be related to some elements of the gear system. These elements were partially or not completely considered in the numerical model, such as coupling, bearings and shafts. 
Acknowledgements. The authors wish to thank M. Philippe Velex of "Laboratoire de Mécanique des contacts de l'INSA de Lyon France" for his support of this research.

\section{References}

[1] M. Maatar, P. Velex, T. Nguyen, M. Octrue, J.L. Vasseur, Experimental and Numerical analysis of transmission errors in spur gear drives, J. Machine Vibration 4 (1995) $8-13$

[2] P. Velex, M. Maatar, A mathematical model for analysing the influence of shape deviations and mounting errors on gear dynamic behaviour, J. Sound Vibration 5(191) 1996 629-660

[3] P. Velex, D. Berthe, Meshing and Eccentricity Contributions to the Dynamic Tooth Loading, Proc. 5th IFToMM Int. Conf. On Rotordynamics, Lyon 1990, 219-224
[4] M. Ben Amar, Matériaux et endommagement des engrenages, DEA École Centrale de Lyon, France, 1995

[5] M. Maatar, P. Velex, Quasi-Static and Dynamic Analysis of Narrow-Faced Helical Gears with Profile and Lead Modifications, A.S.M.E. J. Mechanical Design 119 (1997) 474-480

[6] P. Velex, A. Saada, Modal Analysis for the prediction of Dynamic Tooth loads in Geared Trains. Proc. 3rd J.S.M.E, Int. Conf. On Motion and Power Transmission, Hiroshima 1991, 117-122

[7] M. Maatar, Contribution à l'analyse du comportement dynamique de réducteurs à engrenages simple étage ; influence des écarts de forme et des défauts de montage, Thèse de doctorat : Institut National des Sciences Appliquées de Lyon, 1995

[8] M. Benton, A. Seireg, Simulation of Resonances and Instability Conditions in Pinion-Gear Systems, J. Mechanical Design; Trans. A.S.M.E., (1978) 100(1) 26-31 